\title{
Wing morph- and age-related differences in fertilization success of adult males of a flightless bug, Pyrrhocoris apterus (Heteroptera: Pyrrhocoridae)
}

\author{
RADOMÍR SOCHA \\ Biology Centre ASCR, Institute of Entomology, Branišovská 31, CZ-370 05 České Budějovice, Czech Republic; \\ e-mail:socha@entu.cas.cz
}

Key words. Copulation, fertilization success, egg hatchability, adult males, wing morph, Pyrrhocoris apterus

\begin{abstract}
The aim of the present study was to test the hypothesis that short-winged (brachypterous) and long-winged (macropterous) adult males of a flightless bug Pyrrhocoris apterus differ in fertilization success. For this purpose, 5, 10 and 28 days old brachypterous and macropterous males were mated for the same period of time with reproductively active 5 days old brachypterous females. The average hatchability of five egg batches of these females was used as a measure of the fertilization success of the males. The results revealed significantly higher hatchability of the eggs laid by females that copulated with 5 or 10 days old brachypterous males than with same-aged macropterous males. In contrast, the average hatchability of eggs of females that copulated with 28 days old brachypterous males was significantly lower than of those mated with same-aged macropterous males. It is the first report of wing morph- and age-related differences in fertilization success of males in insects with a non-functional wing-polymorphism. The possible relationship between wing- and age-related differential fertilization and the mating success of $P$. apterus males, and differences in the amount of secretion transferred from their accessory glands into the reproductive tract of females during copulation, is discussed.
\end{abstract}

\section{INTRODUCTION}

The widespread occurrence of dispersal polymorphisms among insects is consistent with the hypothesis that fitness costs are associated with flight capability. Although the trade-off between flight capability and reproduction is well documented in the females of many wingpolymorphic insect species, the relationship between reproductive success and the dispersal capability of males is poorly understood and unknown in males of insects with secondarily evolved flightlessness (Zera \& Denno, 1997; Langellotto et al., 2000). The firebug Pyrrhocoris apterus (L.) is a typical representative of this group of insects (Honěk, 1995; Socha \& Zemek, 2000a) producing flightless long-winged (macropterous) and short-winged (brachypterous) individuals (Socha, 1993). Macroptery in this heteropteran is determined by a recessive allele, which is controlled by photoperiod and temperature (Honěk, 1976, 1986; Socha, 2001). Macropterous individuals of $P$. apterus differ from brachypters in various physiological and behavioural parameters, e.g. longer preoviposition period (Honěk, 1985; Socha \& Šula, 1996), lower feeding and digestive enzyme activities (Socha et al., 1997, 1998), higher adipokinetic response and titre of adipokinetic hormone in CNS (Socha \& Kodrík, 1999; Kodrík et al., 2003) and enhanced dispersal by walking (Socha \& Zemek, 2000b, 2003). These data indicate that these two morphs in P. apterus differ in their life history strategies.

Recently it was shown that the greater tendency of flightless macropters of $P$. apterus to disperse is associated with lower mating activity (Socha, 2004; Socha \& Zemek, 2004a, b) as in many flying wing-polymorphic insects (Zera \& Denno, 1997). Macropterous pairs of this bug copulated almost three times less frequently than brachypterous pairs (Socha \& Zemek, 2004a). This is because of the lower receptivity and smaller gonads of macropterous females, and the lower mating vigour of macropterous males (Socha, 2004; Socha \& Zemek, 2004b). The 3-14 days old brachypterous males were 2-4 times more successful in competing for females than their counterparts (Socha, 2006). With increasing age, the situation changes and 28 days old macropterous males are more successful at mating and competing for females than brachypterous males of the same age. The mating success of males is positively related with accessory glands (AGs) size (Socha, 2006). The extirpation of the corpora allata (CA), the source of juvenile hormone (JH), and application of an active $\mathrm{JH}$ analogue showed that age- and wing morph-related differences in the mating success of $P$. apterus males and its relation to differences in the rate of growth of the AGs, are JH-dependent (Socha et al., 2004; Socha, 2006). These results are supported also by the report that the differences in maturation of AGs in brachypterous and macropterous males are dependent on the volume of CA (Socha \& Hodková, 2006).

However, it is not known if the age- and wing morphrelated differences in mating success of brachypterous and macropterous males of $P$. apterus are associated with their different capability to fertilize females. To test this was the main aim of the present study. This work will provide important information on the functional aspects of flightlessness and provide additional insights into the reproductive strategy of insects with non-functional wingpolymorphism. 
TABLE 1. Fertilization tests involving a 120 min period of mating between 5 days old males of two wing morphs and 5 days old brachypterous females

\begin{tabular}{lcccc}
\hline Males & $\begin{array}{c}\text { No. of } \\
\text { egg batch }\end{array}$ & $\begin{array}{c}\text { No. of eggs } \\
\text { Means } \pm \text { S.D. }\end{array}$ & $\begin{array}{c}\text { No. of larvae } \\
\text { Means } \pm \text { S.D. }\end{array}$ & $\begin{array}{c}\text { Egg hatch- } \\
\text { ability (\%) }\end{array}$ \\
\hline B & 1 & $58.90 \pm 8.54$ & $41.1 \pm 17.37$ & 69.78 \\
M & 1 & $53.33 \pm 9.22$ & $21.67 \pm 19.27$ & 40.63 \\
B & 2 & $56.80 \pm 10.75$ & $38.30 \pm 16.69$ & 67.43 \\
M & 2 & $54.89 \pm 11.47$ & $6.22 \pm 8.67$ & 11.34 \\
B & \multirow{2}{*}{3} & $58.80 \pm 7.64$ & $31.10 \pm 24.50$ & 52.89 \\
M & & $51.89 \pm 15.05$ & $1.67 \pm 2.55$ & 3.21 \\
B & \multirow{2}{*}{5} & $56.89 \pm 6.64$ & $26.00 \pm 20.94$ & 45.70 \\
M & & $49.88 \pm 7.01$ & $3.75 \pm 9.45$ & 7.52 \\
B & \multirow{2}{*}{5} & $56.11 \pm 7.01$ & $23.11 \pm 20.31$ & 41.19 \\
M & & $54.13 \pm 16.30$ & $2.50 \pm 5.95$ & 4.62 \\
\hline
\end{tabular}

Abbreviations and explanations. $\mathrm{B}$ - brachypterous males; $\mathrm{M}-$ macropterous males. 9 or 10 pairs were mated for each male morph.

\section{MATERIAL AND METHODS}

\section{Experimental animals}

Stock cultures of Pyrrhocoris apterus that produce brachypterous and macropterous adults (Socha et al., 1997, 1998) were used in the present study. They originated from individuals collected in fields in the vicinity of České Budějovice, Czech Republic $\left(48^{\circ} 59^{\prime} \mathrm{N}, 14^{\circ} 28^{\prime} \mathrm{E}\right)$. Larvae and adults were kept in mass culture in 0.51 glass jars (approximately 40 specimens per jar), supplied with linden seeds and water in glass tubes plugged with cotton wool, and maintained under a long-day (18L : 6D) photoperiod and constant temperature of $26 \pm 1{ }^{\circ} \mathrm{C}$ as described earlier (Socha, 2004, 2006).

\section{Fertilization tests and evaluation of egg hatchability}

Fertilization success of 5, 10 and 28 days old brachypterous and macropterous males was based on their ability to fertilize reproductively active brachypterous females, i.e. according to the hatchability of the eggs laid by these females. For this purpose, freshly emerged brachypterous and macropterous adult males were removed from the breeding cultures and after reaching a particular age were individually mated with a 5 days old reproductively active brachypterous females, i.e. females at their highest attractiveness and receptivity (Žd'árek, 1970). The fertilization tests did not include mating adult males of the two wing morphs with 5 days old macropterous females, because their mating activity, receptivity and sexual attractiveness is almost as low as those of diapausing females (Socha, 2004; Socha \& Zemek, 2004a). All the bugs tested, including both males and females, were virgins and used only once. These tests were carried out in small Petri dishes $(\varnothing=6 \mathrm{~cm})$ with linden seeds and water, under a long-day $(18 \mathrm{~L}: 6 \mathrm{D})$ photoperiod and $26 \pm 1{ }^{\circ} \mathrm{C}$. In these tests, $9-13$ males of the brachypterous or macropterous morph each copulated with a 5 days old virgin brachypterous female for $120 \mathrm{~min}$. This copulation period gives the highest egg hatchability and is in good agreement with the data reported earlier (Socha \& Zemek, 2004a). In all these tests, the copulation period was timed from the genital contact between males and females. The copulation lasted without interruption for the whole copulation period. After $120 \mathrm{~min}$, the males were removed and each female kept separately in individual Petri dishes $(\varnothing=6 \mathrm{~cm})$, supplied with linden seeds and water under the same photoperiodic and temperature conditions. Five successive egg batches laid by each of mated female were
TABLE 2. Fertilization tests involving a $120 \mathrm{~min}$ period of mating between 10 days old males of two wing morphs and 5 days old brachypterous females.

\begin{tabular}{|c|c|c|c|c|}
\hline Males & $\begin{array}{l}\text { No. of } \\
\text { egg batch }\end{array}$ & $\begin{array}{c}\text { No. of eggs } \\
\text { Means } \pm \text { S.D. }\end{array}$ & $\begin{array}{l}\text { No. of larvae } \\
\text { Means } \pm \text { S.D. }\end{array}$ & $\begin{array}{l}\text { Egg hatch- } \\
\text { ability (\%) }\end{array}$ \\
\hline B & \multirow{2}{*}{1} & $49.91 \pm 11.05$ & $33.36 \pm 14.85$ & 66.85 \\
\hline M & & $50.62 \pm 11.51$ & $33.00 \pm 18.65$ & 65.20 \\
\hline B & \multirow{2}{*}{2} & $45.18 \pm 21.92$ & $34.55 \pm 19.55$ & 76.46 \\
\hline M & & $53.00 \pm 17.38$ & $34.00 \pm 22.19$ & 64.15 \\
\hline B & \multirow{2}{*}{3} & $44.18 \pm 16.73$ & $27.64 \pm 17.02$ & 62.55 \\
\hline M & & $53.15 \pm 11.43$ & $23.54 \pm 22.90$ & 44.28 \\
\hline B & \multirow{2}{*}{4} & $44.45 \pm 19.45$ & $25.36 \pm 18.66$ & 57.06 \\
\hline M & & $56.77 \pm 11.48$ & $14.08 \pm 22.43$ & 24.80 \\
\hline B & \multirow{2}{*}{5} & $45.11 \pm 18.02$ & $16.44 \pm 20.22$ & 36.45 \\
\hline M & & $52.85 \pm 8.44$ & $10.08 \pm 14.69$ & 19.07 \\
\hline
\end{tabular}

Abbreviations and explanations. B - brachypterous males; $\mathrm{M}-$ macropterous males. 11 to 13 pairs were mated for each male morph.

kept separately in Petri dishes until they hatched. Hatchability of five individual egg batches laid by each mated female was subsequently determined and the values averaged. The average values for the hatchability of eggs batches produced by brachypterous females mated with brachypterous males were compared with those produced by brachypterous females that mated with macropterous males.

To avoid the possible effect of rhythmic changes, the bugs were all mated at the same time of day, 9-10 h a.m, i.e. 2-3 h after the light was switched on. This time was chosen on the basis of previous studies that indicate that maximum mating (Socha \& Zemek, 2004a) and walking (Socha \& Zemek, $2000 \mathrm{~b}$ ), and highest content of adipokinetic hormone (Kodrík et al., 2003) and intensity of the adipokinetic response (Maxová et al., 2001) in P. apterus adults occur during the photophase, irrespective of morph.

\section{Data presentation and statistical analyses}

The graphs and statistical evaluation of the results were made using the software Graph Pad Prism, version 4.0 (San Diego, CA, USA). The statistical comparisons of the numbers of eggs, the number that hatched, and the percentage hatchability of five egg batches laid by females mated with same-aged males of two wing morphs in isolated couples were performed using t-test or contingency tables followed by Fisher's exact test (Siegel \& Castellan, 1988). The graph showing the average percentage hatchability of all five successive egg batches laid by females that copulated with 5,10 or 28 days old males of both morphs includes the lower and upper confidence intervals (Glass \& Hopkins, 1996)

\section{RESULTS}

\section{Wing morph- and age-related differences in fertilization success}

The comparative data obtained from the fertilization tests, involving the average numbers of eggs in 5 individual successive egg batches and the average numbers of larvae that hatched from them, are summarized in Tables $1-3$. The results show a considerably higher fertilization capability of 5 days old brachypterous males compared to that of same-aged macropterous males (Table 1). Despite the decrease in egg hatchability related with increase of 
TABLE 3. Fertilization tests involving a $120 \mathrm{~min}$ period of mating between 28 days old males of two wing morphs and 5 days old brachypterous females.

\begin{tabular}{lcccc}
\hline Males & $\begin{array}{c}\text { No. of } \\
\text { egg batch }\end{array}$ & $\begin{array}{c}\text { No. of eggs } \\
\text { Means } \pm \text { S.D. }\end{array}$ & $\begin{array}{c}\text { No. of larvae } \\
\text { Means } \pm \text { S.D. }\end{array}$ & $\begin{array}{c}\text { Egg hatch- } \\
\text { ability (\%) }\end{array}$ \\
\hline B & 1 & $54.44 \pm 7.81$ & $38.67 \pm 20.06$ & 71.02 \\
M & & $49.00 \pm 17.76$ & $38.33 \pm 20.51$ & 78.23 \\
B & 2 & $51.11 \pm 13.70$ & $36.44 \pm 21.33$ & 71.30 \\
M & & $54.00 \pm 14.17$ & $41.58 \pm 16.45$ & 77.01 \\
B & \multirow{2}{*}{3} & $52.33 \pm 10.93$ & $30.33 \pm 22.92$ & 57.96 \\
M & & $52.25 \pm 12.96$ & $29.58 \pm 25.02$ & 56.62 \\
B & \multirow{2}{*}{$53.78 \pm 14.66$} & $15.89 \pm 18.56$ & 29.55 \\
M & & $50.92 \pm 17.60$ & $27.00 \pm 27.52$ & 53.03 \\
B & 5 & $54.44 \pm 12.34$ & $8.11 \pm 17.33$ & 14.90 \\
M & & $51.58 \pm 14.00$ & $17.08 \pm 24.95$ & 33.12 \\
\hline
\end{tabular}

Abbreviations and explanations. $\mathrm{B}$ - brachypterous males; $\mathrm{M}-$ macropterous males. 9 to 12 pairs were mated for each male morph.

the number of egg batches, the average percentage hatchability of successive egg batches was found to be significantly higher $(P<0.0001-0.0336)$ in tests with brachypterous males $(41.19-69.78 \%)$ than with macropterous males (3.21-40.63\%). Similar decreasing trends in the egg hatchability with increasing number of egg batches and significantly higher average percentages of egg hatchability (Fisher'test, $P<0.0001$ ) were recorded also in the 3 rd $(62.55 \%$ vs. $44.28 \%)$, 4 th $(57.06 \%$ vs. $24.80 \%)$ and 5 th $(36.45 \%$ vs. $19.07 \%)$ egg batches laid by females that copulated with 10 days old brachypterous males than of females mated with macropterous males of the same age (Table 2). In contrast, for copulations with 28 days old males the average percentage egg hatchability was significantly higher $(P<0.0001)$ for matings with macropterous than same-aged brachypterous males, but only for the 4th $(53.03 \%$ vs. $29.55 \%)$ and 5 th $(33.12 \%$ vs. $14.90 \%$ ) egg batches (Table 3). Nevertheless, the total average percentages of egg hatchability evaluated for all the egg batches laid by females that copulated with 28 days old males of both morphs were also significantly higher $(P<0.0001)$ for the matings with macropterous males.

When the average percentages of hatchability of all 5 successive egg batches laid by females that copulated with 5,10 or 28 days old males of the two morphs were compared using the Fisher's exact test, the percentages were found to be significantly higher in the tests with 5 and 10 days old brachypterous males $(P<0.0001)$ than with same-aged macropterous males, but significantly lower in tests with 28 days old brachypterous males $(P<$ $0.0001)$ than with macropterous males of the same age (Fig. 1).

These results demonstrate that wing morph affects the fertilization capability of $P$. apterus males and the increase in fertilization success with age of macropterous males.

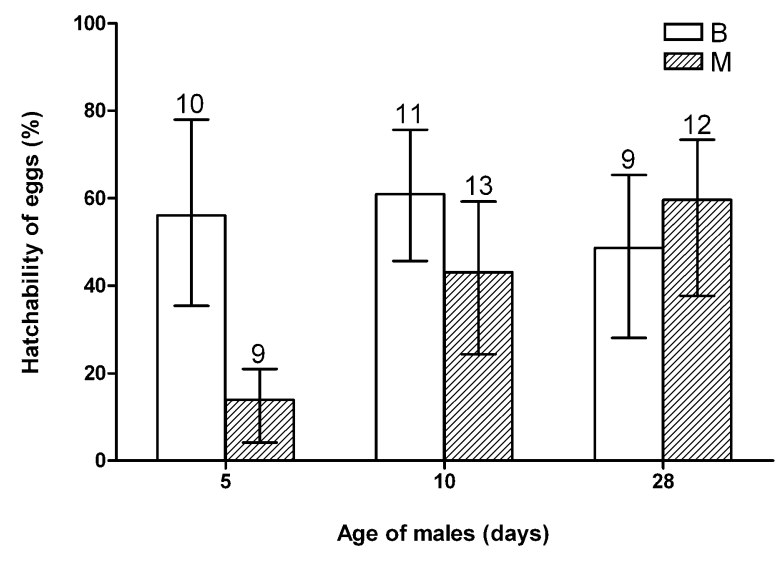

Fig. 1. The average percentage egg hatchability of 5 successive egg batches laid by 5 days old brachypterous females after a 120 min copulation with 5,10 or 28 days old brachypterous or macropterous males of $P$. apterus. Abbreviations: $\mathrm{B}$ - brachypterous males; $\mathrm{M}$ - macropterous males. The numbers above the bars are the number of pairs. Vertical lines indicate the lower and upper limits of the $95 \%$ confidence intervals (Glass \& Hopkins, 1996).

\section{DISCUSSION}

\section{The role of wing morph- and age-related fertilization success in $P$. apterus}

In a competitive setting 5 and 10 days old brachypterous males have a two- to fourfold mating advantage over macropterous males in flying wing-polymorphic insects (Langellotto et al., 2000). Recent studies demonstrate that young brachypterous males also have a mating advantage over macropterous males in P. apterus (Socha, 2004, 2006), in which the macropterous adults have fully developed flight muscles but have lost the ability to fly (Socha \& Šula, 2006). The present study shows that the higher mating success of 5 and 10 days old brachypterous males of this bug is associated with their fertilization success or siring capability, i.e. a higher capability of fertilizing females. When mated for the same period of time with virgin 5 days old brachypterous females, 5 and 10 days old brachypterous males sired more offspring than macropterous males of the same age. In contrast, the siring capability of 28 days old macropterous males is higher than that of same-aged brachypterous males. It cannot be excluded, therefore, that the postponed sexual maturity of males and females of the macropterous morph might play a role in the maintenance of wing polymorphism in $P$. apterus. On the other hand, the higher dispersal activity of young macropterous adults of this bug might result in the spread of genes for macroptery to new areas. In summary, the present study demonstrates that $P$. apterus is characterized by age- and wing morph-related differences in the fertilization success of males.

Our recent studies reveal a trade-off between dispersal and reproduction in flightless macropterous females of $P$. apterus (Socha, 2004, 2007; Socha \& Zemek, 2003), which involves flight muscle development vs. ovarian growth (Socha, 2004, 2007; Socha \& Šula, 2006). This phenomenon is reported in many flying insects and is 
referred to as the "oogenesis-flight" syndrome (Johnson, 1969). However, because macropterous adults of both sexes of $P$. apterus disperse only by walking, the trade-off between dispersal and reproduction in this group of insects is termed "oogenesis-walking" syndrome (Socha, 2004). The lower mating (Socha, 2006) and fertilization success (present results) of macropterous males as well as the lower mating and reproductive capability of macropterous females (Socha, 2004; Socha \& Zemek, $2004 \mathrm{a}, \mathrm{b})$ are coupled with their higher walking and dispersal activity (Socha \& Zemek, 2003). As there are only a few studies on the trade-off between dispersal capability and reproductive success in males and those only for flying insects (Zera \& Denno, 1997; Langellotto et al., 2000), the present study is the first to provide support for a trade-off between dispersal capability and reproductive success in macropterous males in an insect with secondarily evolved flightlessness.

\section{The possible mechanisms underlying wing morph-related differences in fertilization success of males}

In $P$. apterus, the lower mating and competitive capability of macropterous males is a result of their lower mating vigour and lower ability to overcome the rejective behaviour of females of both wing morphs (Socha, 2004; Socha \& Zemek, 2004a, b). No selective rejection of macropterous males by females was observed. The present study reveals that the low mating success of macropterous males of $P$. apterus is associated also with a low fertilization success. Lower mating activity and siring by macropterous males compared with brachypterous males is reported also for the flying wing-dimorphic planthopper Prokelisia dolus (Langellotto et al., 2000). According to these authors, the possible explanation for the brachypter's siring advantage might result from a larger sperm load, more efficient sperm delivery during copulation, or cryptic female choice. However, the mechanisms underlying the siring advantage of brachypterous males of $P$. apterus are unclear. Two factors might be implicated in the higher siring advantage of brachypterous compared with macropterous males. The first is a difference in sperm load; the second is the amount of secretion that is transferred from the male accessory reproductive glands into the spermathecae of females during copulation.

Male reproductive success in insects is supposed to be related to the relative number of sperm transferred and copulation duration (Heady, 1993; Simmons et al., 1996). Despite the possibility that differences in sperm load between brachypterous and macropterous males may contribute to the siring advantage of brachypters, this possibility has not been explored for any planthopper species, including Prokelisia dolus, or any other wingpolymorphic insect (Langellotto et al., 2000). As the results of the present study indicate that the average hatchability of eggs decreases with increasing number of egg batches and sperm transfer commences right from the start of copulation in the firebug P. apterus (Schöfl \& Taborsky, 2002), then either a smaller amount of sperm is transferred by macropterous males into the spermathecae of females during copulation or sperm storage and survival in the reproductive tract of females mated with these males was somewhat lower than in females mated with brachypterous males.

Several papers demonstrate a positive relationship between the size of testes and sperm competition, and show that the size of the internal reproductive organs is an important determinant of male reproductive success (Gage, 1994). There are significant differences in whole gonad mass between the short- and long-winged males e.g. in the cricket Gryllus firmus (Crnokrak \& Roff, 2002). However, because these authors did not measure the testis and AGs separately, they could not distinguish which parts of the male gonads were positively correlated with the wing morph-related differences in mating success. While the association of testis length with variation in the intensity of sperm competition is well documented for many taxa, only a few studies address the importance of the size of male internal reproductive organs in determining other components of male reproductive success. Recently it was shown that the mating success of $P$. apterus males is positively correlated with the size of their AGs (Socha, 2006) and not with the size of their testes or their total protein content (Socha \& Šula, unpubl. data). Thus, the size of the AGs is an important critical determinant of sexual maturity and the level of mating success of $P$. apterus males. A positive relation between male mating frequency and the size of the AGs and not between the mating success and the length of testes is reported also for wing-monomorphic species, e.g. the fruit fly, Drosophila melanogaster (Bangham et al., 2002) and stalk-eyed fly, Cyrtodiopsis dalamanni (Baker et al., 2003; Rogers et al., 2005). It is well known that components in the seminal fluid from the AGs act in many ways to maximize a male's reproductive success and are important for sperm transfer, nourishment, protection, survival and the competition between sperm in the reproductive tract of females (for reviews see e.g. Wolfner, 2002; Chapman \& Davies, 2004; Poiani, 2006). In $P$. apterus, it is the significantly greater amounts of $\mathrm{JH}$ dependent $53 \mathrm{kDa}$ glycoprotein in the AGs of 3- to 14day-old brachypterous compared with the same-aged macropterous males (Socha et al., 2004), which appear to be involved in more efficient sperm storage and fertilization of females. It is probable that different amount of this and/or some other specific proteins in the AGs secretion transferred by males of the two wing morphs might in part be responsible for differences in sperm survival in the reproductive tract of females and consequently also in wing morph-related differences in the fertilization success of $P$. apterus males. All the above data favour the notion that it is not the sperm load but the load of secretion from the male AGs that determines the siring advantage of young brachypterous over macropterous males of $P$. apterus found in the present study.

In summary, the present study for the first time demonstrates that there are wing- and age-related differences in the fertilization success of adult males in a flightless 
wing-polymorphic insect. The wing morph- and agerelated differences in the reproductive success of males are most probably associated with differences in the reproductive and dispersal strategies of two wing morphs in $P$. apterus. It is proposed that different amount of secretion transferred from the male accessory glands into the reproductive tract of females during copulation underlies the wing morph-related differences in fertilization success of males in P. apterus. To confirm this, more detailed studies and specific experiments are necessary.

ACKNOWLEDGEMENTS. This study was supported by the Institute of Entomology project Z50070508 (Academy of Sciences of the Czech republic) and by grant No. 522/07/0788 from the Grant Agency of the Czech Republic. The author thanks D. Rienesslová for technical assistance.

\section{REFERENCES}

Baker R.H., Denniff M., Futerman P., Fowler K., PomianKOWSKi A. \& CHAPMAN T. 2003: Accessory gland size influences time to sexual maturity and mating frequency in the stalk-eyed fly, Cyrtodiopsis dalmanni. Behav. Ecol. 14: $607-611$.

Bangham J., Chapman T. \& Partridge L. 2002: Effects of body size, accessory gland and testis size on pre- and postcopulatory success in Drosophila melanogaster. Anim. Behav. 64: 915-921.

Chapman T. \& Davies S.J. 2004: Functions and analysis of the seminal fluid proteins of male Drosophila melanogaster fruit flies. Peptides 25: 1477-1490.

Crnokrak P. \& Roff D.A. 2002: Trade-offs to flight capability in Gryllus firmus: the influence of whole-organism respiration rate on fitness. J. Evol. Biol. 15: 388-398.

GAGE M.J.G. 1994: Association between body size, mating pattern, testis size and sperm length across butterflies. Proc. $R$. Soc. Lond. (B) 258: 247-254.

Glass G.H. \& Hopkins K.D. 1996: Statistical Methods in Education and Psychology. Allyn and Bacon, Boston, London.

HeADy S.E. 1993: Factors affecting female sexual receptivity in the planthopper, Prokelisia dolus. Physiol. Entomol. 18: 263-270.

HONĚK A. 1976: The regulation of wing polymorphism in natural populations of Pyrrhocoris apterus (Heteroptera, Pyrrhocoridae). Zool. Jb. Syst. 103: 547-570.

HoNĚK A. 1985: Ecophysiological differences between brachypterous and macropterous morphs in Pyrrhocoris apterus (Heteroptera, Pyrrhocoridae). Acta Entomol. Bohemoslov. 82: 347-354.

HoNĚK A. 1986: Inheritance of wing form in Pyrrhocoris apterus. J. Hered. 77: 465-467.

HoNĚK A. 1995: Factors and consequences of a non-functional alary polymorphism in Pyrrhocoris apterus (Heteroptera: Pyrrhocoridae). Res. Popul. Ecol. 37: 111-118.

Johnson C.G. 1969: Migration and Dispersal of Insects by Flight. Methuen, London, xxii + 764 pp.

Kodrík D., Socha R. \& SyrovÁ Z. 2003: Developmental and diel changes of adipokinetic hormone in CNS and haemolymph of the flightless wing-polymorphic bug, Pyrrhocoris apterus (L.). J. Insect Physiol. 49: 53-61.

KuBLi E. 2003: Sex-peptides: seminal peptides of the Drosophila male. Cell Mol. Life Sci. 60: 1689-1704.

Langellotto G.A., Denno R.F. \& Ott J.R. 2000: A trade-off between flight capability and reproduction in males of a wing-dimorphic insect. Ecology 81: 865-875.
Maxová A., Kodrík D., Zemek R. \& Socha R. 2001: Diel changes in adipokinetic response and walking activity of Pyrrhocoris apterus (L.) (Heteroptera) in relation to physiological status and wing dimorphism. Eur. J. Entomol. 98: 433-438.

PoIANI A. 2006: Complexity of seminal fluid: a review. Behav. Ecol. Sociobiol. 60: 289-310.

Rogers D.W., Chapman T., Fowler K. \& Pomiankowski A. 2005: Mating-induced reduction in accessory reproductive organ size in the stalk-eyed fly Cyrtodiopsis dalmanni. BMC Evol. Biol. 5: 37-42.

SchÖFl G. \& TABORSKy M. 2002: Prolonged tandem formation in firebugs (Pyrrhocoris apterus) serves mate-guarding. Behav. Ecol. Sociobiol. 52: 426-433.

Siegel S. \& Castellan N.J. JR. 1988: Nonparametric Statistics for the Behavioral Sciences. McGraw-Hill, New York, 399 pp.

Simmons L.W., Stockley P., Jackson R.L. \& Parker G.A. 1996: Sperm competition or sperm selection: no evidence for female influence over paternity in yellow dung flies Scatophaga stercoraria. Behav. Ecol. Sociobiol. 38: 199-206.

SochA R. 1993: Pyrrhocoris apterus (Heteroptera) - an experimental model species: a review. Eur. J. Entomol. 90: 241-286.

SochA R. 2001: Latitudinal gradient in response of wing polymorphism to photoperiod in a flightless bug, Pyrrhocoris apterus (Heteroptera: Pyrrhocoridae). Eur. J. Entomol. 98: 167-169.

SocHA R. 2004: Decreased mating propensity of macropterous morph in a flightless wing-polymorphic insect, Pyrrhocoris apterus (L.) (Heteroptera). Eur. J. Entomol. 101: 539-545.

SocHA R. 2006: Endocrine control of wing morph-related difference in mating success and accessory gland size in male firebugs. Anim. Behav. 71: 1273-1281.

SocHA R. 2007: Factors terminating ovarian arrest in longwinged females of a flightless bug, Pyrrhocoris apterus (Heteroptera: Pyrrhocoridae). Eur. J. Entomol. 104: 15-22.

Socha R. \& Hodková M. 2006: Corpus allatum volumedependent differences in accesory gland maturation in longand short-winged males of Pyrrhocoris apterus (Heteroptera: Pyrrhocoridae). Eur. J. Entomol. 103: 27-32.

SocHA R. \& Kodrík D. 1999: Differences in adipokinetic responses of Pyrrhocoris apterus (Heteroptera) in relation to wing dimorphism and diapause. Physiol. Entomol. 24: 278-284.

Socha R. \& Šula J. 1996: Differences in haemolymph proteins in relation to diapause and wing dimorphism in Pyrrhocoris apterus (L.) (Heteroptera: Pyrrhocoridae). J. Comp. Physiol. (B) 166: 382-387.

Socha R. \& Šula J. 2006: Flight muscles polymorphism in a flightless bug, Pyrrhocoris apterus (L.): Developmental pattern, biochemical profile and endocrine control. J. Insect Physiol. 52: 231-239.

SochA R. \& ZEMEK R. 2000a: Wing movement behavior in longand short-winged morphs of flightless bug Pyrrhocoris apterus L. (Heteroptera: Pyrrhocoridae). J. Insect Behav. 13: 741-750.

Socha R. \& ZEMEK R. 2000b: Locomotor activity in adult Pyrrhocoris apterus (Heteroptera) in relation to sex, physiological status and wing dimorphism. Physiol. Entomol. 25: 383-389.

Socha R. \& ZEMEK R. 2003: Wing morph-related differences in the walking pattern and dispersal in a flightless bug, Pyrrhocoris apterus (L.) (Heteroptera). Oikos 100: 35-43.

SochA R. \& ZEMEK R. 2004a: Mating behaviour and wing morph-related differences in the sexual activity of a flightless 
bug, Pyrrhocoris apterus (L.) (Heteroptera). Ethol. Ecol. Evol. 16: $217-229$.

Socha R. \& ZEMEK R. 2004b: Wing morph-related differences in the pattern of mating activity in a flightless bug, Pyrrhocoris apterus (L.) (Heteroptera). Inv. Reprod. Dev. 46: 11-18.

Socha R., Šula J. \& ZemeK R. 1997: Feeding, drinking and digestive enzyme activities in short- and long-day females of Pyrrhocoris apterus (Heteroptera). Physiol. Entomol. 22: 161-169.

Socha R., Šula J. \& Zemek R. 1998: Feeding behaviour, digestive physiology and lipid content in macropterous females of Pyrrhocoris apterus (L.) (Heteroptera: Pyrrhocoridae). Physiol. Entomol. 23: 91-96.
Socha R., Šula J. \& KodRík D. 2004: Wing morph-related differences in developmental pattern of accessory gland proteins in adult males of Pyrrhocoris apterus (L.) and their endocrine control. J. Insect Physiol. 50: 893-901.

WoLfNer M.F. 2002: The gifts that keep on giving: physiological functions and evolutionary dynamics of male seminal proteins in Drosophila. Heredity 88: 85-93.

Zera A.J. \& Denno R.F. 1997: Physiology and ecology of dispersal polymorphism in insects. Annu. Rev. Entomol. 42: 207-231.

ŽĎ́́ReK J. 1970: Mating behaviour in the bug, Pyrrhocoris apterus L. Heteroptera): ontogeny and its environmental control. Behaviour 37: 253-268.

Received April 13, 2007; revised and accepted June 6, 2007 